\title{
Time to Initiation of Treatment with Polymyxin B Cartridge Hemoperfusion in Septic Shock Patients
}

\author{
Naoshi Takeyama $^{a}$ Hiroshi Noguchi $^{a} \quad$ Akihiko Hirakawa $^{a}$ Hideki Kano $^{a}$ Kazuma Morino ${ }^{b}$ \\ Toru Obata $^{c}$ Tetsuya Sakamoto ${ }^{d}$ Fumihiro Tamai ${ }^{\mathrm{e}}$ Hiroyasu Ishikura $^{\mathrm{f}}$ Youichi Kase $^{\mathrm{g}}$

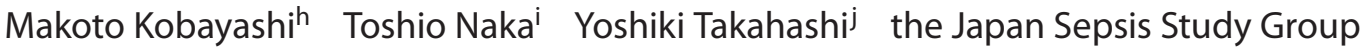 \\ ${ }^{a}$ Department of Emergency and Acute Intensive Care Medicine, Fujita Health University, Toyoake, ${ }^{b}$ Department of \\ Acute Medicine, Yamagata Prefectural Medical Center for Acute Medicine, Yamagata, 'Department of Surgery, Shiga \\ University of Medical Science Hospital, Seta, ${ }^{\mathrm{d}}$ Department of Emergency Medicine, Trauma and Critical Care Center, \\ Teikyo University School of Medicine, Tokyo, ${ }^{e}$ Department of Emergency Medicine, Oita Sanai Medical Center, Oita, \\ fDepartment of Emergency and Critical Care Medicine, Fukuoka University Faculty of Medicine, Fukuoka, ${ }^{9}$ Department \\ of Anesthesiology, Jikei University School of Medicine, Tokyo, ${ }^{\mathrm{h}}$ Tajima Emergency and Critical Care Medical Center, \\ Toyooka, 'Department of Critical Care Medicine, Wakayama Medical University, Wakayama, and 'Department of \\ Emergency Medicine, Showa University, Tokyo, Japan
}

\section{Key Words}

Polymyxin B · Hemoperfusion • Septic shock • Sequential Organ Failure Assessment score - Timing of initiation • Pulmonary oxygenation $\cdot$ Catecholamine $\cdot$ Multicenter cohort study

\begin{abstract}
Background: We investigated whether early initiation of hemoperfusion with a polymyxin B cartridge (PMX) after the diagnosis of septic shock could improve the clinical outcome. Methods: A prospective, open-labeled, multicenter cohort study was performed at intensive care units in Japan. 41 patients received $P M X$ within $6 \mathrm{~h}$ after the diagnosis of septic shock (early group) and 51 patients were treated after 6 h (late group). Results: The early group had a significantly shorter duration of ventilator support and also had a lower catecholamine requirement. PMX was effective for improvement of hypotension, hypoperfusion, the sequential organ failure assessment score, and pulmonary oxygenation regardless of the timing of its initiation. The 28-day mortality
\end{abstract}

\section{KARGER}

E-Mail karger@karger.ch www.karger.com/bpu

\section{(C) 2012 S. Karger AG, Basel $0253-5068 / 12 / 0334-0252 \$ 38.00 / 0$}

Karger Open access

This is an Open Access article licensed under the terms of the Creative Commons Attribution- NonCommercial-NoDerivs 3.0 License (www.karger.com/OA-license), applicable to the online version of the article only. Distribution for non-commercial purposes only. rate did not differ between the two groups. Conclusions: Early initiation of PMX shortened the duration of ventilator support and also reduced the catecholamine requirement, so early treatment of septic shock should achieve a better outcome.

Copyright $\odot 2012$ S. Karger AG, Basel

\section{Introduction}

The lipopolysaccharide of endotoxin has been well characterized as one of the most potent triggers of the inflammatory cascade during acute sepsis $[1,2]$. Hemoperfusion with a cartridge containing polymyxin B immobilized on polystyrene fibers (PMX) has been employed to selectively absorb endotoxin in patients with Gram-negative sepsis [3, 4]. It has been demonstrated to effectively neutralize the pathogenic activity of endotoxin and has been shown to reduce organ dysfunction [3].

In patients with severe sepsis or septic shock, early detection of global tissue hypoxia and hemodynamic optimi- 
zation within $6 \mathrm{~h}$ has been shown to reduce overall mortality [5]. Accordingly, the present study was carried out to verify whether early initiation of PMX improved the clinical outcome in patients with severe sepsis or septic shock.

\section{Materials and Methods}

\section{Patients}

This study was conducted at the intensive care units of 35 Japanese hospitals from April 2006 to March 2008. The ethics committee at each hospital approved the study protocol, and informed consent was obtained from each patient or a relative or other legal representative. Subjects were required to meet both of the following criteria: (1) presence of a systemic inflammatory response to infection according to the consensus definition of the American College of Chest Physicians/Society of Critical Care Medicine Consensus Conference Committee [6], and (2) either a systolic blood pressure $<90 \mathrm{~mm} \mathrm{Hg}$ after fluid infusion $(20 \mathrm{ml} / \mathrm{kg})$ or a sequential organ failure assessment (SOFA) cardiovascular score $\geq 2$ (namely, at least dopamine was necessary to maintain blood pressure) [7]. The exclusion criteria included terminal cancer, terminal hematological illness, severe hepatic dysfunction (total bilirubin $\geq 10 \mathrm{mg} / \mathrm{dl}$ and hepaplastin test $\leq 40 \%$ ), and refusal to give written consent.

\section{Procedures}

The cartridge for PMX was produced by immobilizing polymyxin B on polystyrene fibers $(0.005 \mathrm{~g}$ of polymyxin B to $1 \mathrm{~g}$ of fibers) by covalent bonding (Toraymyxin; Toray Industries, Tokyo, Japan). Patients received direct hemoperfusion with PMX in addition to standard medical therapy for sepsis. Vascular access was obtained via a double-lumen venous catheter. Hemoperfusion with PMX was usually carried out for $2 \mathrm{~h}$ at each session. The second PMX session was performed $24 \mathrm{~h}$ after the end of the first session. Nafamostat mesilate, low molecular weight heparin, or unfractionated heparin was used as the anticoagulant.

\section{Data Collection}

Patients were followed up for 28 days after enrollment, and clinical data were obtained from an established registry database and included the site of infection, the Acute Physiology and Chronic Health Evaluation (APACHE) II score [8], the SOFA score, results of bacterial culture and laboratory tests, hemodynamic variables, and therapeutic interventions. The plasma endotoxin level was measured by the Endospecy test [9] at baseline and $6 \mathrm{~h}$ after the first PMX session.

\section{End-Points}

The primary end-point was the 28 -day mortality rate. The secondary end-points included changes from baseline to 7 days of the mean arterial pressure (MAP), use of catecholamines, serum lactate level, $\mathrm{PaO}_{2} / \mathrm{F}_{\mathrm{i}} \mathrm{O}_{2}$ ratio, and SOFA score. The ventilator-free rate was assessed at 14 days.

\section{Statistical Analysis}

Statistical analysis was performed by using commercially available SPSS software (SPSS Inc.). Results are presented as the median and $95 \%$ confidence interval (CI). Comparison of numerical values between two groups was done with either Student's $t$
Table 1. Baseline characteristics of treatment groups

\begin{tabular}{|c|c|c|c|}
\hline Characteristics & $\begin{array}{l}\text { Early group } \\
(\mathrm{n}=41) \\
\text { median } \\
(95 \% \mathrm{CI})\end{array}$ & $\begin{array}{l}\text { Late group } \\
(\mathrm{n}=51) \\
\text { median } \\
(95 \% \mathrm{CI})\end{array}$ & $\begin{array}{l}\mathrm{p} \\
\text { value }\end{array}$ \\
\hline Age, years & $66(61,70)$ & $68(64,72)$ & 0.40 \\
\hline Male, n (\%) & $32(78)$ & $35(69)$ & 0.32 \\
\hline Body weight, kg & $62(52,71)$ & $60(55,64)$ & 0.65 \\
\hline Site of infection, $\mathrm{n}(\%)$ & & & 0.50 \\
\hline Abdomen & $19(46)$ & $27(53)$ & - \\
\hline Respiratory tract & $7(17)$ & $9(18)$ & - \\
\hline Urinary tract & $5(12)$ & $6(12)$ & - \\
\hline Skin/soft tissue & $6(15)$ & $3(6)$ & - \\
\hline Others & $4(10)$ & $6(12)$ & - \\
\hline \multicolumn{4}{|l|}{ Gram staining of bacteria, $\mathrm{n}(\%)$} \\
\hline Gram positive & $17(55)$ & $21(51)$ & 0.76 \\
\hline Gram negative & $24(77)$ & $38(93)$ & 0.07 \\
\hline APACHE II score & $26(23,29)$ & $23(21,25)$ & 0.12 \\
\hline SOFA score & $11(10,12)$ & $12(11,13)$ & 0.25 \\
\hline MAP, $\mathrm{mm} \mathrm{Hg}$ & $72(66,78)$ & $70(66,75)$ & 0.68 \\
\hline Catecholamine weaning, $\mathrm{n}(\%)$ & $0(0)$ & $0(0)$ & - \\
\hline Lactate, $\mathrm{mg} / \mathrm{dl}$ & $54(38,69)$ & $35(29,42)$ & $0.03^{\mathrm{a}}$ \\
\hline $\mathrm{PaO}_{2} / \mathrm{F}_{\mathrm{i}} \mathrm{O}_{2}$ & $250(196,303)$ & $222(179,265)$ & 0.42 \\
\hline \multicolumn{4}{|c|}{ Other indicators of disease severity, $\mathrm{n}(\%)$} \\
\hline Mechanical ventilation & $35(85)$ & $43(84)$ & 0.89 \\
\hline Renal replacement therapy & $21(51)$ & $31(61)$ & 0.36 \\
\hline Onset to PMX & $3.5(2.9,4.0)$ & $27.2(18.9,35.5)$ & $<0.001^{\mathrm{a}}$ \\
\hline The number of PMX sessions & $1.8(1.7,1.9)$ & $1.7(1.5,1.8)$ & $0.23^{\mathrm{a}}$ \\
\hline
\end{tabular}

Patients in the early group were treated with PMX within $6 \mathrm{~h}$, patients in the late group were not treated with PMX within $6 \mathrm{~h}$. Range of APACHE II score was $0-71$, with low scores indicating better organ function. Range of SOFA score was $0-24$, with lower scores indicating better organ function. ${ }^{\text {a }}$ Welch's test.

test or the Mann-Whitney U test. Mortality was estimated by the Kaplan-Meier method and compared between two groups by the log-rank test. The influence of the time until PMX and the number of PMX sessions was estimated by Welch's test. Ventilator-free days were compared with the Cox proportional hazards regression model after adjustment for the $\mathrm{PaO}_{2} / \mathrm{F}_{\mathrm{i}} \mathrm{O}_{2}$ ratio.

\section{Results}

\section{Characteristics of the Patients}

A total of 120 patients were enrolled. 28 patients were excluded because follow-up could not be continued for 28 days or because the time from the onset of shock until starting PMX was unclear. As a consequence, 92 patients were analyzed. Of these 92 patients, 41 underwent with PMX within $6 \mathrm{~h}$ after the diagnosis of septic shock (early group) and 51 received PMX after more than $6 \mathrm{~h}$ (late group). The two groups received the same basal therapy (including early goal-directed therapy, renal replacement therapy, PMX sessions, and ventilator support), had a 
Table 2. Outcome measures at baseline and on day 7 in both groups

\begin{tabular}{|c|c|c|c|c|c|}
\hline & \multicolumn{2}{|l|}{ Baseline } & \multicolumn{2}{|l|}{ Day 7} & \multirow{2}{*}{$\begin{array}{l}\text { Baseline vs. day } 7 \\
\mathrm{p} \text { value } \\
\text { within group }\end{array}$} \\
\hline & $\begin{array}{l}\text { mean } \\
(95 \% \mathrm{CI})\end{array}$ & $\begin{array}{l}\mathrm{p} \text { value } \\
\text { between groups }\end{array}$ & $\begin{array}{l}\text { mean } \\
(95 \% \mathrm{CI})\end{array}$ & $\begin{array}{l}\mathrm{p} \text { value } \\
\text { between groups }\end{array}$ & \\
\hline \multicolumn{6}{|l|}{ Lactate, mg/dl } \\
\hline Early group & $54(38,69)$ & 0.03 & $39(22,55)$ & 0.15 & 0.009 \\
\hline Late group & $35(29,41)$ & & $25(16,34)$ & & 0.022 \\
\hline \multicolumn{6}{|l|}{ MAP, mm Hg } \\
\hline Early group & $72(66,78)$ & 0.68 & $85(78,91)$ & 0.29 & 0.001 \\
\hline Late group & $70(66,75)$ & & $80(75,86)$ & & 0.001 \\
\hline \multicolumn{6}{|c|}{$\mathrm{PaO}_{2} / \mathrm{F}_{\mathrm{i}} \mathrm{O}_{2}, \mathrm{~mm} \mathrm{Hg}$} \\
\hline Early group & $250(196,303)$ & 0.42 & $322(269,375)$ & $0.11^{\mathrm{a}}$ & 0.003 \\
\hline Late group & $222(179,265)$ & & $271(229,312)$ & & 0.013 \\
\hline \multicolumn{6}{|l|}{ SOFA } \\
\hline Early group & $11(10,12)$ & 0.25 & $9(8,11)$ & 0.46 & 0.004 \\
\hline Late group & $12(11,13)$ & & $10(8,11)$ & & 0.001 \\
\hline
\end{tabular}

Lactate normal range is $3-20 \mathrm{mg} / \mathrm{dl}$. ' Welch's test.

similar distribution of age, gender, and body weight, and had a comparable severity of sepsis (APACHE II and SOFA scores), as well as similar bacterial species and etiologic factors (table 1). The time from the onset of shock to initiation of PMX was significantly shorter in the early group than in the late group.

The two groups did not differ with respect to the baseline MAP or $\mathrm{PaO}_{2} / \mathrm{F}_{\mathrm{i}} \mathrm{O}_{2}$ ratio, but the plasma level of lactate was higher in the early group than in the late group (table 2).

\section{Primary and Secondary End-Points}

The 28 -day mortality rate was $39 \%$ (16/41 patients) in the early group and $35 \%$ (18/51 patient) in the late group ( $\mathrm{p}=0.76$; fig. 1$)$.

In both the early and late groups, PMX improved MAP, the lactate level, the SOFA score, and the $\mathrm{PaO}_{2} / \mathrm{F}_{\mathrm{i}} \mathrm{O}_{2}$ ratio from baseline to day 7 (table 2). The plasma endotoxin level did not change significantly after the first PMX session, being $18.4 \mathrm{pg} / \mathrm{ml}(95 \%$ CI $3.5-33.3 \mathrm{pg} / \mathrm{ml})$ at baseline and $27.7 \mathrm{pg} / \mathrm{ml}$ (95\% CI $1.6-53.9 \mathrm{pg} / \mathrm{ml})$ afterwards.

On day 7, the lactate level, MAP, SOFA score, and $\mathrm{PaO}_{2} / \mathrm{F}_{\mathrm{i}} \mathrm{O}_{2}$ were not significantly different between the two groups (table 2). However, weaning from catecholamines by day 7 after PMX was more frequent in the early group (22/41 patients) than in the late group (17/51 patients) (54 vs. $33 \%$; $\mathrm{p}=0.050)$. Also, the duration of ventilator support was significantly shorter in the early group than the late group (adjusted hazards ratio 2.06; 95\% CI 1.04-4.09; $\mathrm{p}=0.039$ ) (fig. 2).

\section{Discussion}

To evaluate whether the time until initiation of PMX influenced septic shock-induced organ dysfunction and the clinical outcome, we compared patients who received PMX within $6 \mathrm{~h}$ after the diagnosis of septic shock and patients who started treatment from $6 \mathrm{~h}$ onward. We found that starting PMX within $6 \mathrm{~h}$ after the diagnosis of septic shock significantly shortened the duration of ventilator support and also reduced the catecholamine requirement. PMX was effective for improvement of hypotension, hypoperfusion, and pulmonary oxygenation regardless of the timing of its initiation.

Our results were similar to the findings of previous studies [10-12], which showed that survivors commenced PMX earlier after the onset of shock than patients who died. In patients with severe sepsis or septic shock, early administration of appropriate antibiotics, corticosteroids, and recombinant human activated protein $\mathrm{C}$ are all associated with better survival [13]. Thus, initiation of such therapies as well as PMX as soon as possible after diagnosis of severe sepsis or septic shock may be very important for achieving a good outcome.

The clinical benefit of PMX for hypotension and hypoperfusion identified in the present study is in good agreement with previous reports [14-16], but the effect of PMX on pulmonary oxygenation is less clear. Only two randomized controlled trials have been published that assessed the effect of PMX on pulmonary oxygenation. Vincent et al. [17] reported that there was no significant 


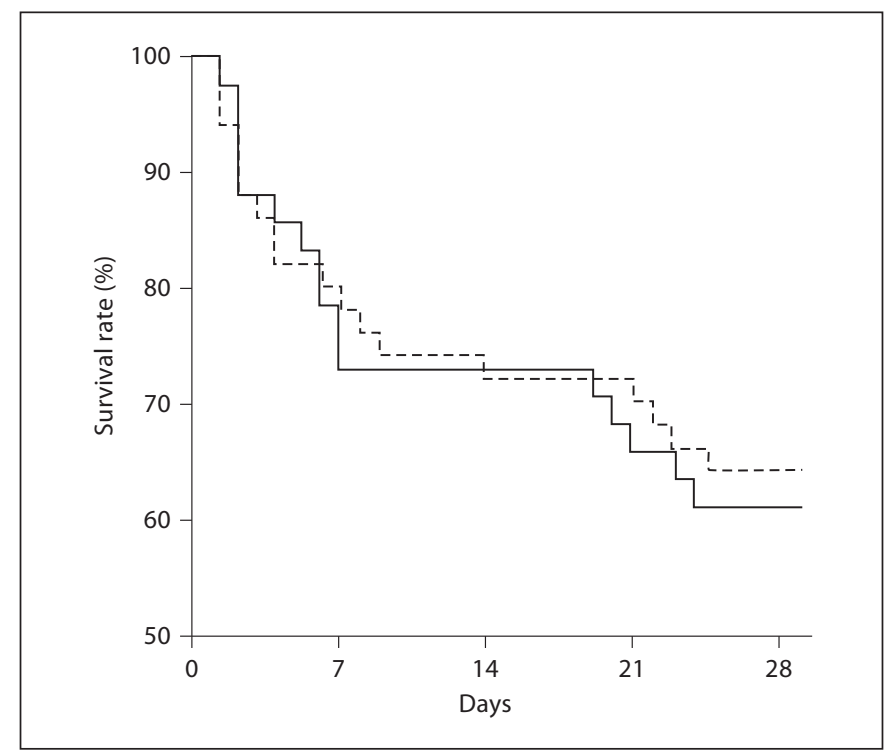

Fig. 1. Kaplan-Meier survival analysis: survival of the early group (black line) and the late group (dotted line) was not significantly different (log-rank test, $\mathrm{p}=0.76)$.

improvement of the $\mathrm{PaO}_{2} / \mathrm{F}_{\mathrm{i}} \mathrm{O}_{2}$ ratio in the PMX group, while a more recent study by Cruz et al. [18] showed that the $\mathrm{PaO}_{2} / \mathrm{F}_{\mathrm{i}} \mathrm{O}_{2}$ ratio increased slightly in the $\mathrm{PMX}$ group compared with the conventional therapy group.

Both in vivo and in vitro studies have indicated that absorption of endotoxin and its removal from the circulation is a major mechanism by which PMX improves septic shock $[3,19]$. In this study, however, the endotoxin level did not decrease after PMX. Although some studies have demonstrated that PMX reduces the circulating endotoxin level in septic patients $[2,10,14]$, another study did not confirm this [17]. Even though patients with little or no circulating endotoxin, including those with Grampositive infections, were enrolled in our study, a beneficial effect of PMX on hypoperfusion and pulmonary oxygenation was observed regardless of the pathogens causing sepsis. Thus, the response to PMX may be related to another mechanism in addition to removal of endotoxin. There have been recent reports about adhesion of activated monocytes and neutrophils [20], as well as anandamide [21] and high mobility group box-1 [22], which act as paracrine mediators of hypotension [23], to the fibers of the polymyxin cartridge. Such findings may partially explain the efficacy of PMX, although the molecular mechanisms remain unclear.

Unfortunately, the small number of patients limited the power to detect significant differences of survival and

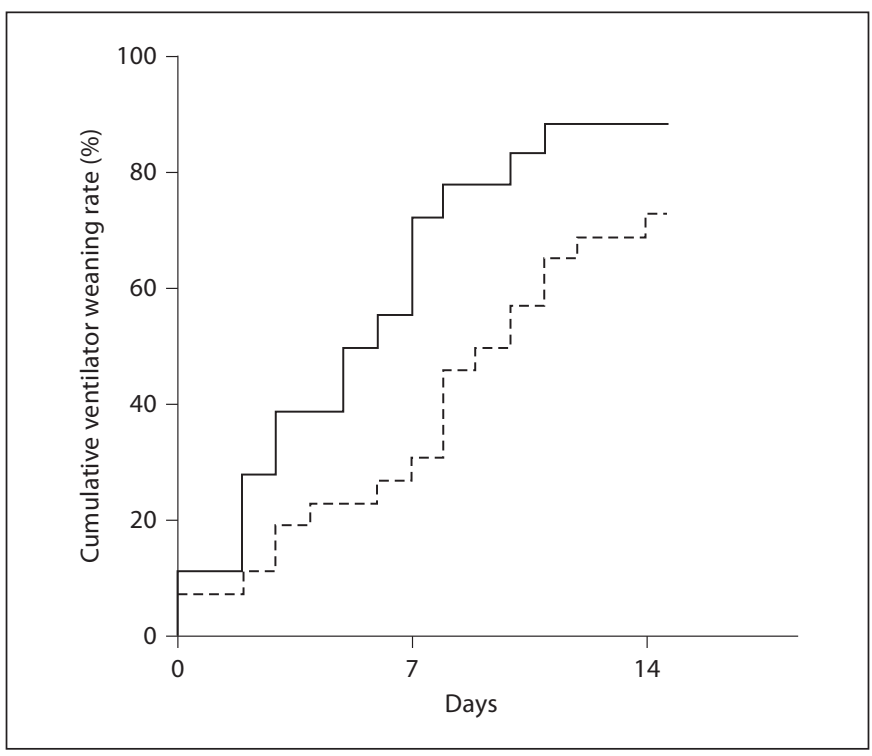

Fig. 2. Ventilator-free rate: the duration of ventilator support was significantly shorter in the early group (black line) than in the late group (dotted line).

catecholamine requirements. A much larger study would be required to more thoroughly investigate the potential improvement of mortality with early initiation of PMX.

\section{Acknowledgments and Funding}

The authors would like to thank Ms. Sanae Masuko, Minako Fukushima, Mr. Toru Arakane, and Hisataka Shoji for their valuable comments and advice. There was no funding source.

The members of Japan Sepsis Study Group are as follows (in alphabetical order): Dokkyo Medical University, Saitama: K. Kubota, H. Sakio; Fujita Health University, Aichi: N. Takeyama; Fukuoka University, Fukuoka: H. Ishikura; Gifu Prefectural Tajimi Hospital, Gifu: N. Mabuchi; International University of Health and Welfare Hospital, Tochigi: Y. Shinozawa; Jikei University School of Medicine, Tokyo: Y. Kase; Jikei University Kashiwa Hospital, Chiba: T. Koyama; JR Tokyo Hospital, Tokyo: H. Tanaka; Juntendo University Nerima Hospital, Tokyo: M. Suzuki; Kansai Medical University, Osaka: K. Nishi; Kariya Toyota General Hospital, Aichi: M. Miura; Kawakita General Hospital, Tokyo: Y. Murata; Kawasaki Municipal Kawasaki Hospital, Kanagawa: S. Ito; Kenwakai Hospital, Nagano: E. Kumagai; Kitakyusyu Kenwakai Ohtemachi Hospital, Fukuoka: T. Nishinaka; Koshigaya Hospital Dokkyo University School of Medicine, Saitama: K. Yamada; Masuko Memorial Hospital, Aichi: K. Shigematsu; Matsunami General Hospital, Gifu: S. Akamatsu; Mito Saiseikai General Hospital, Ibaraki: I. Ebihara; Nagano Municipal Hospital, Nagano: S. Tagami; Narita Memorial Hospital, Aichi: T. Ohbayashi; Nihon University School of Medicine Itabashi Hospital, Tokyo: K. Tanjo: Ohhama Daiichi Hospital, 
Okinawa: M. Uechi; Okazaki City Hospital, Aichi: M. Asada; Oita Sanai Medical Center, Oita: F. Tamai; Shinmatsudo Central General Hospital, Chiba: T. Nakamura; Sapporo-Hokuyu Hospital, Hokkaido: M. Yonekawa; Sassa General Hospital, Nagano: S. Takeuchi; Seirei Hamamatsu General Hospital, Shizuoka: T. Isozaki; Shiga University of Medical Science Hospital, Shiga: T. Obata; St. Luke's International Hospital, Tokyo: S. Ishimatsu; Showa University, Kanagawa: Y. Takahashi; Tajima Emergency and Critical Care Medical Center, Hyogo: M. Kobayashi; Teikyo University School of Medicine, Tokyo: T. Sakamoto; Toho University
Omori Medical Center, Tokyo: K. Yoshiwara; Wakayama Medical University, Wakayama: T. Naka; Yamagata Prefectural Medical Center for Acute Medicine, Yamagata: K. Morino.

\section{Disclosure Statement}

The authors have no conflicts of interest to disclose.

\section{References}

$\checkmark 1$ Rietschel ET, Brade H, Holst O, Holst O, Brade L, Muller-Loennies S, Mamat U, Zahringer U, Beckmann F, Seydel U, Brandenburg K, Ulmer AJ, Mattern T, Heine $\mathrm{H}$, Schletter J, Loppnow H, Schonbeck U, Flad HD, Hauschildt S, Schade UF, Di Padova F, Kusumoto S, Schumann RR: Bacterial endotoxin: chemical constitution, biological recognition, host response and immunological detoxification. Curr Top Microbiol Immunol 1996;216:39-81.

-2 Cruz DN, Bellomo R, Ronco C: Clinical effects of polymyxin B-immobilized fiber column in septic patients. Contrib Nephrol. Basel, Karger, 2007, vol 156, pp 444-451.

-3 Shoji H: Extracorporeal endotoxin removal for the treatment of sepsis: endotoxin absorption cartridge (Toraymyxin). Ther Apher Dial 2003;7:108-114.

4 Racholin JS, Foster D, Dellinger RP: Endotoxin removal: how far from the evidence? From EUPHAS to EUPHRATES. Contrib Nephrol. Basel, Karger, 2010, vol 167, pp 111118.

5 Rivers E, Nguyen B, Havstad S, Ressler J, Muzzin A, Knoblich B, Peterson E, Tomlanovich M, Early Goal-Directed Therapy Collaborative Group: Early goal-directed therapy in the treatment of severe sepsis and septic shock. N Engl J Med 2001;345:13681377.

-6 Bone RC, Balk RA, Cerra FB, Dellinger RP, Fein AM, Knaus WA, Schein RM, Sibbald WJ: Definitions for sepsis and organ failure and guidelines for the use of innovative therapies in sepsis. The ACCP/SCCM Consensus Committee. American College of Chest Physicians/Society of Critical Care Medicine. Chest 1982;101:1644-1655.

7 Vincent JL, Moreno R, Takala J, Willatts S, De Mendonça A, Bruining H, Reinhart CK, Suter PM, Thijs LG: The SOFA (Sepsis-related Organ Failure Assessment) score to describe organ dysfunction/failure. On behalf of the Working Group on Sepsis-Related Problems of the European Society of Intensive Care Medicine. Intensive Care Med 1996;22:707-710.

8 Knaus WA, Draper EA, Wagner DP, Zimmerman JE: APACHE II: a severity of disease classification system. Crit Care Med 1985;13: 16 Berto P, Ronco C, Cruz D, Melotti RM, An$818-829$.

$\checkmark 9$ Cohen J: The detection and interpretation of endotoxemia. Intensive Care Med 2000; 26:S51-S56.

10 Tsushima K, Kubo K, Yoshikawa S, Koizumi T, Yasuo M, Furuya S, Hora K: Effects of PMX-DHP treatment for patients with directly induced acute respiratory distress syndrome. Ther Apher Dial 2007;11:138-145.

11 Ikeda T, Ikeda K, Nagura M, Taniuchi H, Matsushita M, Kiuchi S, Kuroki Y, Suzuki K, Matsuno N: Clinical evaluation of PMXDHP for hypercytokinemia caused by septic multiple organ failure. Ther Apher Dial 2004;8:293-298.

12 Shimizu T, Hanasawa K, Sato K, Umeki M, Koga N, Naganuma T, Sato S, Shimonishi T, Ikeda T, Matsuno N, Ono S, Saitoh H, Satoh K, Otani Y, Endo Y, Eguchi Y, Tani T, PMX Treatment Study Group: Direct hemoperfusion with polymyxin-B-immobilized fiber columns improves septic hypotension and reduces inflammatory mediators in septic patients with colorectal perforation. Langenbecks Arch Surg 2009;394:303-311.

13 Dellinger RP, Levy MM, Carlet JM, Bion J, Parker MM, Jaeschke R, Reinhart K, Angus DC, Brun-Buisson C, Beale R, Calandra T, Dhainaut JF, Gerlach H, Harvey M, Marini JJ, Marshall J, Ranieri J, Ramsay G, Sevransky J, Thompson BT, Townsend S, Vender JS, Zimmerman JL, Vincent JL: Surviving Sepsis Campaign: international guidelines for management of severe sepsis and septic shock: 2008. Intensive Care Med 2008;34: 17-60.

-14 Cruz DN, Perazella MA, Bellomo R, de Cal M, Polanco N, Corradi V, Lentini P, Nalesso F, Ueno T, Ranieri VM, Ronco C: Effectiveness of polymyxin B-immobilized fiber column in sepsis: a systematic review. Crit Care 2007;11:R47.

15 Zagli G, Bonizzoli M, Spina R, Cianchi G, Pasquini A, Anichini V, Matano S, Tarantini F, Di Filippo A, Maggi E, Peris A: Effects of hemoperfusion with an immobilized polymyxin-B fiber column on cytokine plasma levels in patients with abdominal sepsis. Minerva Anesthesiol 2010;76:1-8. tonelli M: Cost-effectiveness analysis of polymyxin-B immobilized fiber column and conventional medical therapy in the management of abdominal septic shock in Italy. Blood Purif 2011;32:331-340.

17 Vincent JL, Laterre PF, Cohen J, Burchardi $\mathrm{H}$, Bruining $\mathrm{H}$, Lerma FA, Wittebole X, De Backer D, Brett S, Marzo D, Nakamura H, John S: A pilot-controlled study of a polymyxin B-immobilized hemoperfusion cartridge in patients with severe sepsis secondary to intra-abdominal infection. Shock 2005;23:400-405.

18 Cruz DN, Antonelli M, Fumagalli R, Foltran F, Brienza N, Donati A, Malcangi V, Petrini F, Volta G, Bobbio Pallavicini FM, Rottoli F, Giunta F, Ronco C: Early use of polymyxin B hemoperfusion in abdominal septic shock: the EUPHAS randomized controlled trial. JAMA 2009;301:2445-2452.

19 Hussein MH, Kato T, Sugiura T, Daoud GA, Suzuki S, Fukuda S, Sobajima H, Kato I, Togari $\mathrm{H}$ : Effect of hemoperfusion using polymyxin B-immobilized fiber on IL-6, HMGB1 , and IFN- $\gamma$ in a neonatal sepsis model. Pediatr Res 2005;58:309-314.

20 Kumagai T, Takeyama N, Yabuki T, Harada M, Miki Y, Kanou H, Inoue S, Nakagawa T, Noguchi H: Apheresis of activated leukocytes with an immobilized polymyxin B fiber in patients with septic shock. Shock 2010; 34:461-466.

21 Wang Y, Liu Y, Sarker KP, Nakashima M, Serizawa T, Kishida A, Akashi M, Nakata M, Kitajima I, Maruyama I: Polymyxin B binds to anandamide and inhibits its cytotoxic effect. FEBS Lett 2000;470:151-155.

22 Abe S, Hayashi H, Seo Y, Matsuda K, Kamio K, Saito Y, Usuki J, Azuma A, Kudo S, Gemma A: Reduction in serum high mobility group box-1 level by polymyxin B-immobilized fiber column in patients with idiopathic pulmonary fibrosis with acute exacerbation. Blood Purif 2011;32:310-316.

23 Varga K, Wagner JA, Bridgen DT, Kunos G: Platelet- and macrophage-derived endogenous cannabinoids are involved in endotoxin-induced hypotension. FASEB J 1998;12: 1035-1044. 